\title{
Über Bildung und Zerfall der Phloroglucinkarbonsäure
}

\section{Doctoral Thesis}

Author(s):

Piazza, Giuseppe

Publication date:

1918

Permanent link:

https://doi.org/10.3929/ethz-a-000099656

Rights / license:

In Copyright - Non-Commercial Use Permitted

Originally published in:

Sammelband ETH-BIB 
Dis: ETH: $193 \quad E x-B$

\section{Über Bildung und Zerfall der Phloroglucinkarbonsäure.}

Von

G. Piazza.

Mit 8 Figuren im Text.

Sonderabdruck aus:

„Zeitschrift für physikalișche Chemie“. XCIII. Band. 2. Heft.

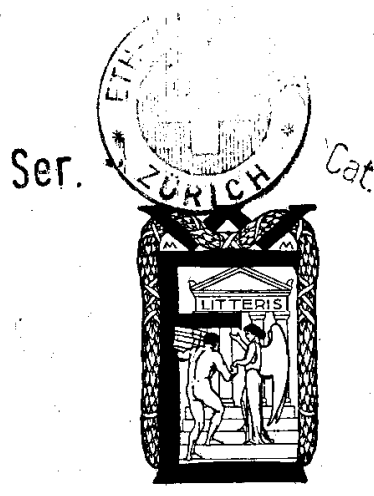

Leipzig, Wilhelm Engelmann, 1918. 
Für die Bildung:

$$
\begin{aligned}
\frac{k_{1}}{k_{2}} & =5 \\
k & =k_{1}+k_{2}=1 \cdot 4 \cdot 10^{-3} \\
k_{1} & =1 \cdot 15 \cdot 10^{-3} \\
k_{2} & =0 \cdot 23 \cdot 10^{-3}
\end{aligned}
$$

Diese Doppelbestimmung ist natürlich widersinnig. Wenn $k$ und $k^{\prime}$ auseinanderfallen, so kann man eben das Gleichgewicht nicht mehr dazu gebrauchen, um die Einzelgeschwindigkeiten in einer für Bildung und Zerfall gleichmässig gültigen Weise zu bestimmen. Geschwindigkeit von Bildung und Rückbildung werden voneinander unabhängig.

\section{Zusammenfassung.}

1. Unter Verwertung der Fluoreszenzauslöschung des Fluoresceins bei der alkalimetrischen Titration wird die Gleichgewichtskonstante der Reaktion: $\mathrm{C}_{6} \mathrm{H}_{2}(\mathrm{OH})_{3} \mathrm{COOK}+\mathrm{H}_{2} \mathrm{O}=\mathrm{HKCO}_{3}+\mathrm{C}_{6} \mathrm{H}_{3}(\mathrm{OH})_{3}$ bestimmt.

2. In einem auf ${ }^{1} / 100^{\circ}$ genauen und mit Schüttelvorrichtung versehenen Thermostaten wird bei $50^{\circ}$ die Geschwindigkeit der Bildung und Zersetzung des phloroglucinkarbonsauren Kaliums gemessen. Die Methode besteht in der Messung der Lichtbrechung mit Hilfe des Löweschen Interferometers.

3. Die Zersetzungsgeschwindigkeit der Phloroglucinkarbonsäure wird durch Titration und Leitfähigkeit bestimmt.

4. Im Gegensatz zu dem gewöhnlichen Verhalten ergibt sich, dass bei gleichen Abständen vom Gleichgewicht die Synthese um ein Mehrfaches langsamer geht, als die Zersetzung.

5. Es wird die Bedeutung dieser Erscheinung für die Gesetze der chemischen Kinetik erörtert.

Vorliegende Arbeit führte ich im physikalisch-chemischen Institut der Eidg. Techn. Hochschule in Zürich aus.

Es ist mir ein Bedürfnis, auch an dieser Stelle Herrn Prof. Dr. E. Baur, dem ich die Anregung zu der Arbeit verdanke, für sein ständiges Interesse und für seine mannigfaltigen Ratschläge besten Dank auszusprechen.

Zürich, Oktober. 1917. 